\title{
POWER LINE CABLE TRANSFER FUNCTION FOR MODELLING OF POWER LINE COMMUNICATION SYSTEM
}

\author{
Petr Mlýnek* - Jiří Mišurec* \\ - Martin Koutný ${ }^{*}$ - Miloš Orgoñ ${ }^{* *}$
}

\begin{abstract}
This paper presents the design of a power line communication model. Primarily, it is focused on a realization of a communication model with a power line channel. The model is composed of a PLC communication model, a model of power lines and a noise model. Power lines are modelled through a chain parameter describing the relation between the input and output voltage and current of the two-port network.
\end{abstract}

K e y w or d s: power line, noise, modelling, simulation, transfer function, two-port network

\section{INTRODUCTION}

PLC (Power Line Communication) technology takes profits from the advantage of not requiring any additional wiring $[1,2]$. On the other hand there are many challenges in using this medium for data communication; all originate from the fact that this medium was designed for distribution of electrical power, not for communication.

PLC systems fall into two areas: broadband PLC and narrowband PLC. Broadband PLC achieves the characteristics of broadband communication, enabling, for example, fast Internet access or implementation of small LAN networks. The broadband technology works in frequency range $150 \mathrm{kHz}$ to $34 \mathrm{MHz}$ and its theoretical maximum speed is $200 \mathrm{Mbit} / \mathrm{s}$ [3, 4]. Narrowband PLC is used mainly for specific services including central management of power consumption, tariffing, remote meter reading, commanding, etc. The narrowband technology works up to a maximum frequency of $150 \mathrm{kHz}$ and its theoretical bit rate is of the order of kilobits (up to $2 \mathrm{Mbit} / \mathrm{s}$ ). The possibility of using the power network and systems of narrow-band PLC is the most recent development [5].

A problematic area of PLC is interference. Interference may affect the service reliability. Also, there is considerable attenuation on the path towards the terminal equipment. From the viewpoint of data transmission, the power line is always mismatched and thus there appear reflections on the line, and the line properties and parameters vary with time and place.

A model of the power line channel is required to simulate PLC communications. There exist two possible methods for modelling the power line channels. The first one applies the methods used for modelling of radio channels. The power line channel is assumed to be a multipath propagation environment. The second alternative applies the methods used to model electricity distribution networks. The chain parameter matrices describing the relation between the input and output voltage and current of a two-port network can be applied to model the transfer function of the communications channel.

This article focuses on realizations of a complex PLC communication system. For the purpose of modelling, PLC communication system can be set up from a PLC communication model, a power line model and a noise model.

The power line is modelled as a transfer function of the two-port network.

\section{PLC COMMUNICATION MODEL}

Computer simulation of PLC systems will enable a better understanding of the topic of data transmission over power lines, it will reveal the potentials of these systems, and the area of PLC applicability will be better defined. Sufficiently precise computer models of PLC systems will thus make the process of selecting and deploying new telemetry and management technologies markedly more effective.

A model will be described with frequency division of the spectrum using the OFDM technique, where particular carrier frequencies are mapped with 256-state, 64-state or 32-state QAM or QPSK and BPSK modulation $[6,7]$. The resulting model is shown in Fig. 1.

Model description [8]: The model was realized in Simulink [9]. A Bernoulli Binary Generator is used as the data source in the proposed model. It is a generator which generates random binary numbers according the Bernoulli distribution. In real systems, Bit allocation

\footnotetext{
* Department of Telecommunications, Faculty of Electrical Engineering and Communication, Brno University of Technology, Czech Republic, mlynek@feec.vutbr.cz, misurec@feec.vutbr.cz, koutnym@feec.vutbr.cz; ${ }^{* *}$ Department of Telecommunication, Faculty of Electrical Engineering and Information Technology, Slovak University of Technology in Bratislava, orgon@ktl.elf.stuba.sk
} 


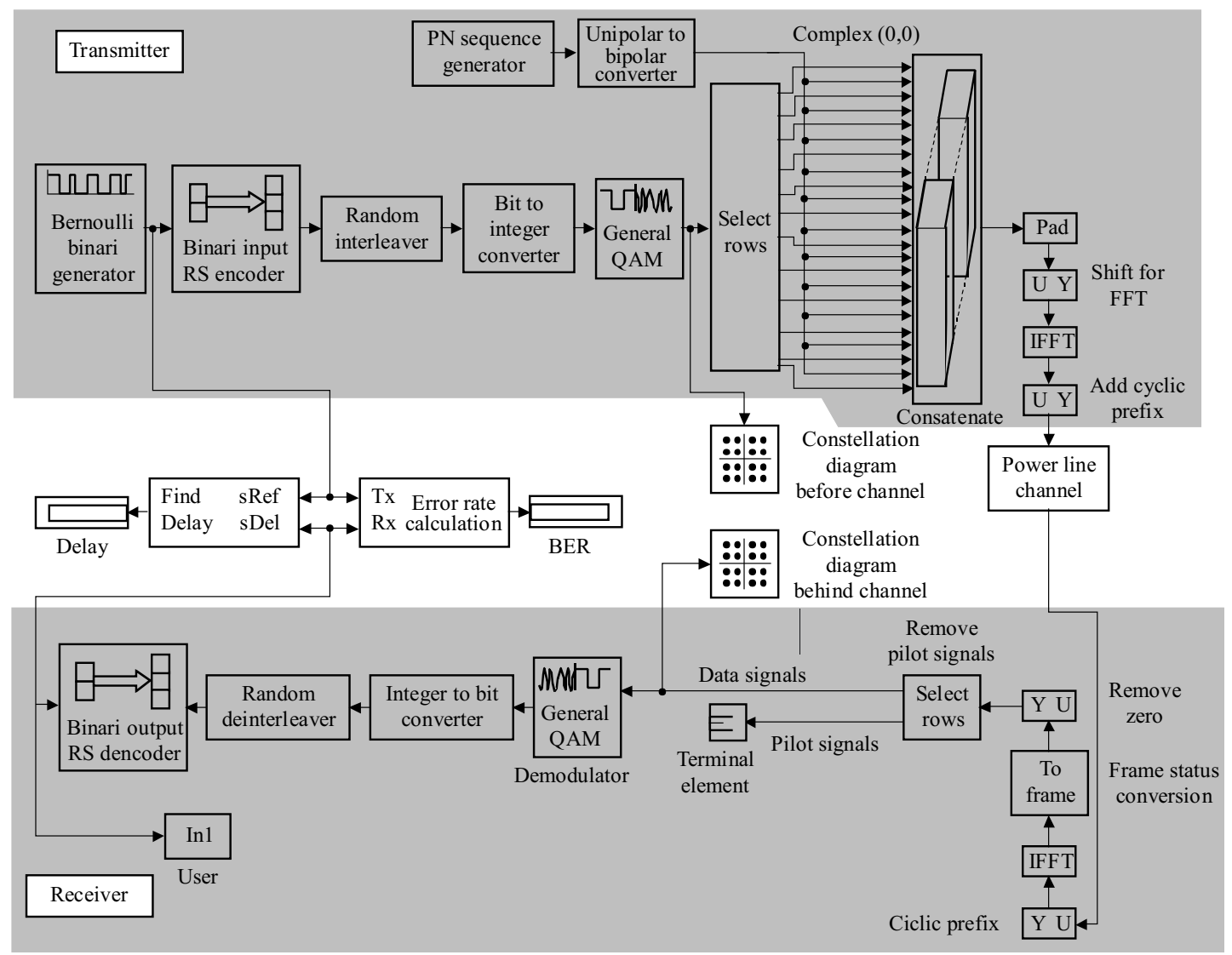

Fig. 1. OFDM model

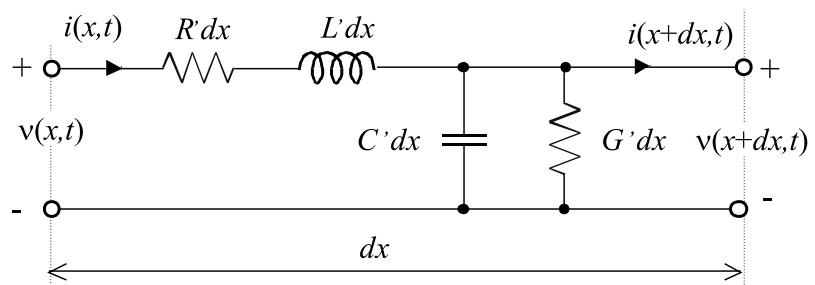

Fig. 2. Elementary cell of a transmission line

(mapping) can be obtained from this equation [10]

$$
b_{n}=\log _{2}\left(1+\frac{3}{\left(Q^{-1} \frac{B E R}{4}\right)^{2}} S N R_{n}\right),
$$

where $b_{n}$ is the number of bits at $n$-subchannel, $S N R_{n}$ is the average signal to noise ratio in partial subchannel $n$, where $Q^{-1}$ is defined as

$$
Q(x)=\frac{1}{\sqrt{2 \pi}} \int_{x}^{\infty} e^{-\frac{y^{2}}{2}} \mathrm{~d} y .
$$

Channel coding, realized by the Reed-Solomon code $(\mathrm{RS}(15 ; 11))$, was used to ensure data transfer in the communication channel.

From the channel coding block we obtain a serial flow of data. This flow enters the mapping block. The bit sequences are converted to a symbol sequence in the block mapping. The distribution of symbols is the result of mapping. This symbols distribution is dependent on the selected modulation.

The sub-band separation of the useful signal is realized in the Select Rows block. It is necessary to insert the pilot signals and implement an estimate of the transmission channel in the case of coherent system detection. This is realized by the help of the PN Sequence Generator.

Block Complex $(0,0)$ is used to generate the middle carrier frequency. Block Concatenate is used to add up all the carrier frequencies which enter this block. The size of the framework is then adjusted for IFFT in the Pad block and the signal is adjusted for IFFT in the Shift block. After that the signal undergoes the Fast Fourier transform, where data are converted from the frequency domain to the time domain.

To avoid intersymbol interference (ISI) the OFDM protective interval is used. It is realized by the Add Cyclic Prefix block.

The blocks for calculating the bit error are used too. The blocks are connected inversely on the receiver side. The channel block will be described in the next chapter.

\section{TRANSMISSION LINE MODEL}

In literature, the methods used to simulate and study the transmission line behaviour are different [11-13]. Most of them are obtained from the time dependent 


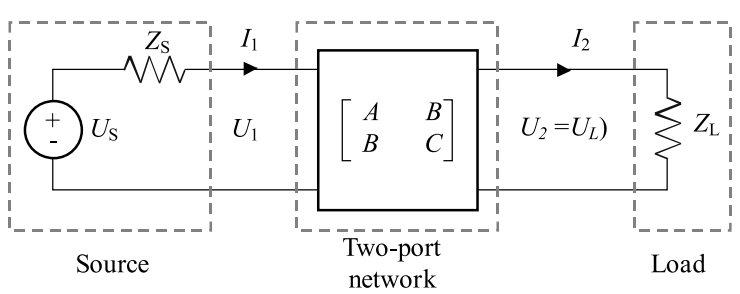

Fig. 3. Two-port network connected to a source and load

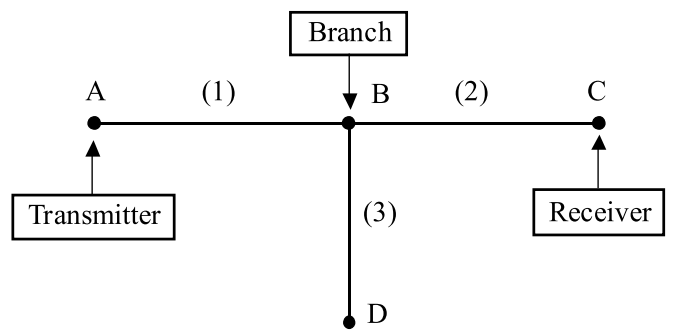

Fig. 4. Topology of the sample network

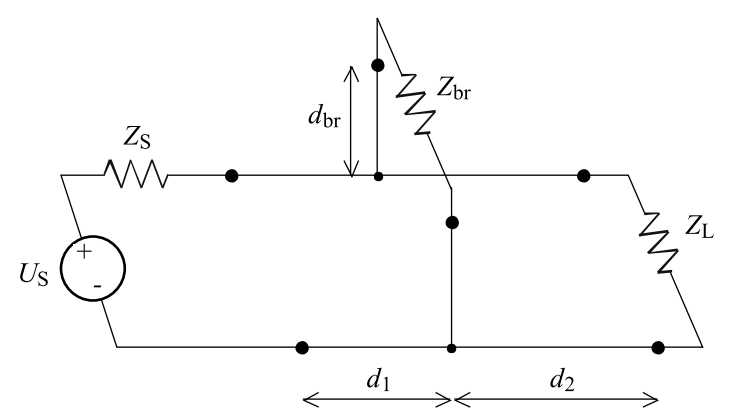

Fig. 5. Transmission line with one bridge tap connection

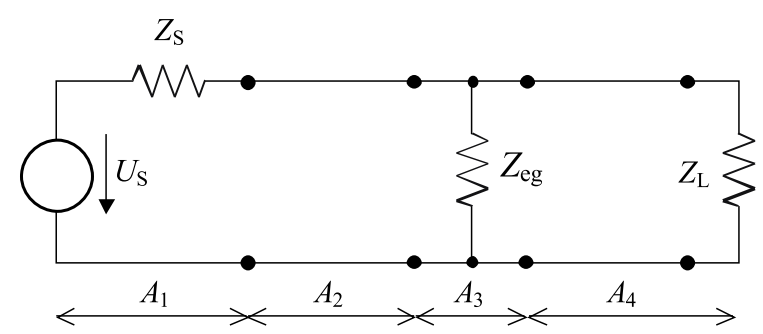

Fig. 6. Equivalent circuit for transmission line with one bridge tap connection

telegrapher's equations which are for the elementary line transmission cell, shown in Fig. 2, the following

$$
\begin{aligned}
& \frac{\partial v(x, t)}{\partial x}+R^{\prime} i(x, t)+L^{\prime} \frac{\partial i(x, t)}{\partial t}=0, \\
& \frac{\partial i(x, t)}{\partial x}+G^{\prime} v(x, t)+C^{\prime} \frac{\partial v(x, t)}{\partial t}=0,
\end{aligned}
$$

In these equations $x$ denotes the longitudinal direction of the line and $R^{\prime}, L^{\prime}, G^{\prime}$ and $C^{\prime}$ are the per unit length resistance $(\Omega / \mathrm{m})$, inductance $(\mathrm{H} / \mathrm{m})$, conductance $(\mathrm{S} / \mathrm{m})$ and capacitance $(\mathrm{F} / \mathrm{m})$, respectively. The electric quantities are dependent on the geometric and constitutive parameters.

The parameters to describe the transmission line are the characteristic impedance $Z_{c}$ and the propagation con- stant $\gamma$

$$
\begin{gathered}
Z_{c}=\sqrt{\frac{R^{\prime}+j \omega L^{\prime}}{G^{\prime}+j \omega C^{\prime}}}, \\
\gamma=\alpha+j \beta=\sqrt{\left(R^{\prime}+j \omega L^{\prime}\right)\left(G^{\prime}+j \omega C^{\prime}\right)} .
\end{gathered}
$$

\section{MODELLING OF THE POWER LINE CHANNEL}

The chain parameter matrices describing the relation between the input and output voltage and current of the two-port network can be applied for modelling the transfer function of the power line channel. This method has been chosen because the topology of the sample distribution network is known.

In Fig. 3, the relation between the input voltage and current and output voltage and current of the two port network can be represented as

$$
\left[\begin{array}{c}
U_{1} \\
I_{1}
\end{array}\right]=\left[\begin{array}{ll}
A & B \\
C & D
\end{array}\right]\left[\begin{array}{c}
U_{2} \\
I_{2}
\end{array}\right]
$$

where $A, B, C$ and $D$ are frequency dependent coefficients.

The transfer function of two-port network is given by equation [14]

$$
H=\frac{U_{L}}{U_{S}}=\frac{Z_{C}}{A Z_{C}+B+C Z_{C} Z_{S}+D Z_{S}} .
$$

The ABCD matrix for the transmission line with characteristic impedance $Z_{c}$, propagation constant $\gamma$ and length $l$ can be calculated as [14]

$$
\left[\begin{array}{c}
U_{1} \\
I_{1}
\end{array}\right]=\left[\begin{array}{cc}
\cosh (\gamma l) & Z_{C} \sinh (\gamma l) \\
\frac{1}{Z_{C}} \sinh (\gamma l) & \cosh (\gamma l)
\end{array}\right]\left[\begin{array}{c}
U_{2} \\
I_{2}
\end{array}\right]
$$

\subsection{Sample network}

The simple distribution network topology is shown in Fig. 4. The link has one branch and consists of segments $(1),(2)$ and (3) with lengths $d_{1}, d_{2}$ and $d_{b r}$ and characteristic impedances $Z_{C 1}, Z_{C 2}$ and $Z_{C 3}$.

Figure 5 shows the transmission line with one bridge tap. We replace the bridge tap with an equivalent impedance (see Fig. 6). The branch cable terminated by the load impedance $Z_{b r}$ can be considered to be the equivalent load impedance $Z_{e q}[14]$

$$
Z_{e q}=Z_{C} \frac{Z_{b r}+Z_{C} \tanh \left(\gamma_{b r} d_{b r}\right)}{Z_{C}+Z_{b r} \tanh \left(\gamma_{b r} d_{b r}\right)}
$$

where $Z_{b r}$ and $\gamma_{b r}$ are characteristic impedance and propagation constant of the branch.

The channel from the source to the load consists of several network sections. Each section can be described 
Table 1. Sample network parameter

\begin{tabular}{cc}
\hline$Z_{S}$ & $120 \Omega$ \\
$Z_{L}$ & $600 \Omega$ \\
$Z_{b r}$ & $300 \Omega$ \\
$Z_{C}$ & $180 \Omega$ \\
$l_{1}$ & $20 \mathrm{~m}$ \\
$l_{2}$ & $30 \mathrm{~m}$ \\
$l_{3}$ & $20 \mathrm{~m}$ \\
$Z_{e q}$ & $97.67-0.669 i \Omega$ \\
\hline
\end{tabular}

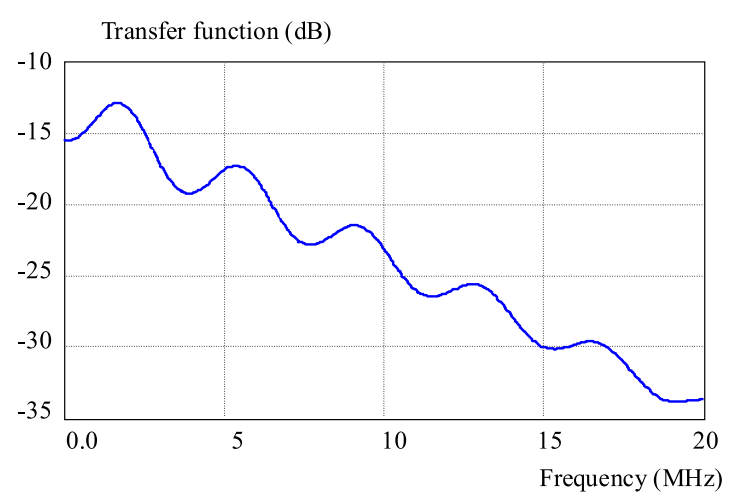

Fig. 7. Simulation of the sample network

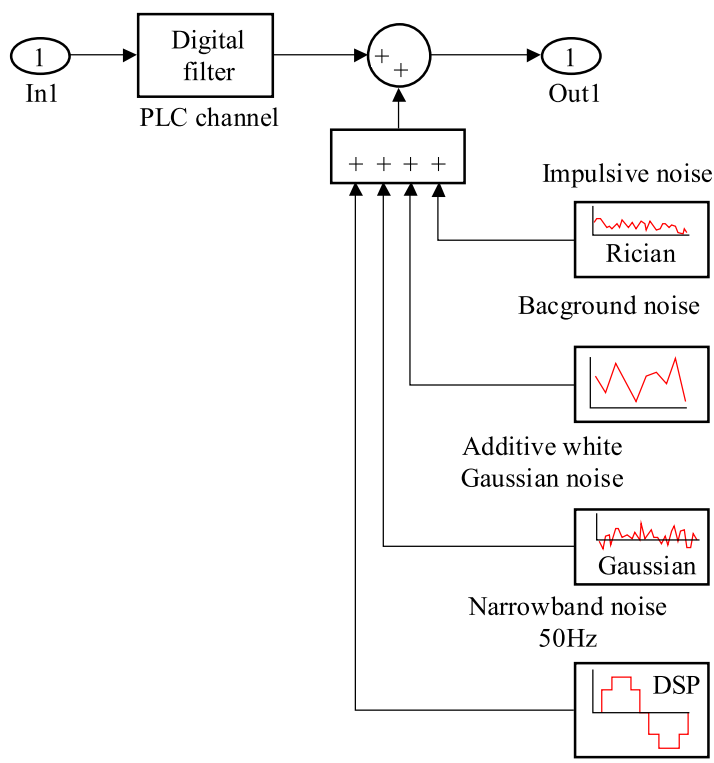

Fig. 8. PLC channel

by a single transmission matrix. The sections are serially connected. The transmission matrix $A$ from the source to the load can be formed applying the chain rule

$$
A=\prod_{i=1}^{n} A_{i},
$$

where $n$ represents the number of network sections. Figure 6 illustrates the section for sample network. The matrices of different sub circuits for the sample network are expressed by the matrix [14]

$$
A_{1}=\left[\begin{array}{cc}
1 & Z_{S} \\
0 & 1
\end{array}\right]
$$

$$
\begin{gathered}
A_{2}=\left[\begin{array}{cc}
\cosh \left(\gamma_{1} d_{1}\right) & Z_{1} \sinh \left(\gamma_{1} d_{1}\right) \\
\frac{1}{Z_{1}} \sinh \left(\gamma_{1} d_{1}\right) & \cosh \left(\gamma_{1} d_{1}\right)
\end{array}\right], \\
A_{3}=\left[\begin{array}{cc}
1 & 0 \\
\frac{1}{Z_{e q}} & 1
\end{array}\right], \\
A_{4}=\left[\begin{array}{cc}
\cosh \left(\gamma_{2} d_{2}\right) & Z_{2} \sinh \left(\gamma_{2} d_{2}\right) \\
\frac{1}{Z_{2}} \sinh \left(\gamma_{2} d_{2}\right) & \cosh \left(\gamma_{2} d_{2}\right)
\end{array}\right] .
\end{gathered}
$$

\subsection{Simulation results}

$R^{\prime}, L^{\prime}, G^{\prime}, C^{\prime}, Z_{C}$ and $\gamma$ parameter were obtained analytically from characteristic parameters of the cable NYM-J 3x2.5.

Figure 7 shows the results of simulation of the sample network based on the transfer function of the two-port network model (9). The reflections at the open tap cause periodical notches in the frequency response, which can easily be seen in Fig. 7 .

Table 1 shows the parameter of sample network.

\section{PLC CHANNEL MODEL}

The coefficients of the filter were calculated from the transfer function of the two-port network (9).

The power line was modelled as a filter together with the sources of the interference. More detailed information about the sources of interference can be found in [15]. Figure 8 shows the resulting PLC channel.

This PLC channel is used in OFDM model in Fig. 1 and allows to simulate data communication over power lines.

\section{CONCLUSION}

The article deals with the design of a PLC communication system model. The model is composed of the OFDM communication model, model of power lines and noise model. The power lines are modelled through a chain parameter describing the relation between the input and output voltage and current of two-port network.

For the sample network topology power lines were modelled and the resulting channel model was constructed consisting of a power line model and the sources of interference.

The work provides a computer apparatus for creating models and modelling power lines for the simulation of data transmission over power lines. The constructed power line model offers the possibility to carry out investigations in different network topologies and study their effect on the communication system.

The complex PLC communication model can be used for comparison of the performance of different modulation and coding schemes and for future standardization. The results of simulations based on the model will be compared with measurements in the future work. 


\section{Acknowledgments}

The research was supported by Ministry of Industry and Trade of the Czech Republic the project No. FRTI1/075, Ministry of Education of the Czech Republic project No. MSM0021630513 and project FEKT-S-10-16. This work is a part of research activities conducted at Slovak University of Technology Bratislava, Faculty of Electrical Engineering and Information Technology, Department of Telecommunications, within the scope of projects VEGA No. 1/0565/09 Modelling of traffic parameters in NGN telecommunication networks and services and ITMS 26240120005 Support for Building of Centre of Excellence for SMART technologies, systems and services.

\section{REFERENCES}

[1] FERREIRA, H. C.-GROVE, H. M.-HOOIJEN, O.-VINCK, A. J. : Power Line Communications: an overview, Proc. of IEEE ISPLC, 1996, pp. 558-563.

[2] ORGOŇ, M.: PLC/BPL and Next Generation Networks, In: POWER-COM - Conference Communication over MV and LV power lines, Praha, 2007.

[3] RÓKA, R.-ORGOŇ, M.: Možnosti nových technológií vysokorýchlostného prenosu multimediálnych signálov na pevných prenosových médiách v prístupovej sieti, EE časopis pre elektrotechniku a energetiku 15 No. 3 (2009), 16-19.

[4] MLYNEK, P.-MISUREC, J.-KOUTNY, M. The Communication Unit for Remote Data Acquisition via the Internet: In Proceedings of the 7th WSEAS International Conference on Circuits, Systems, Electronics, Control and Signal Processing (CSES'08), Puerto de La Cruz, Spain, WSEAS Press, 2008, pp. $168-173$.

[5] MISUREC, J.: The Data Acquisition via PLC in Energetics, In 32nd International Conference on Telecommunications and Signal Processing - TSP'2009, pp. 1-4.

[6] KRAJSA, O.-SILHAVY, P.-KOUTNY, M. : Half-Overlapped Filtered MultiTone Modulation for PowerLine Communication Systems, In Proceedings of the 13th WSEAS International Conference on Systems, Rhodos, WSEAS Press, 2009, pp. 596-599.

[7] KRAJSA, O.-SILHAVY, P.: Half-Overlapped Filtered MultiTone Modulation, its Implementation and Comparison with Non-Overlapped Filtered MultiTone Modulation, In Proceedengs of The 7th WSEAS International Conference on Circuits, Systems, Electronics, Control \& Signal Processing, 1, Puerto De La Cruz, Spain, WSEAS, 2008, pp. 272-27.

[8] KOUTNY, M.-KRAJSA, O.-MLYNEK, P.: Modelling of PLC Communication for Supply Networks, In Proceedings of the 13th WSEAS International Conference on Communication, Rhodos, WSEAS Press, 2009, pp. 185-189.

[9] The MathWorks [online]. 1999 [cit. 2010-05-05]. http://www.mathworks.com.

[10] BINGHAM, J. A. C.: Multicarrier Modulation for Data Transmission: An Idea whose Time Has Come, IEEE Communication Magazine 25 No. 5 (1990), 5-14.

[11] DOSTERT, K. M.: Power Lines as High Speed Data Transmission Channels - Modelling the Physical Limits, Proceedings of the 5th IEEE International Symposium on Spread Spectrum Techniques and Applications (ISSSTA 98), Sep. 1998, pp. 585-589.

[12] HARDY, M. E.-ARDALAN, S.-O'NEAL, J. B.-GALE, L. J.-SHUEY, K. C.: A Model for Communication Signal Propagation on Three Phase Power Distribution Lines, IEEE Transactions on Power Delivery 6 No. 3 (July 1991), 945-951.
[13] MENG, H.-CHEN, S.-GUAN, L.-LAW, C. L.-SO, P. L.-GUNAWAN, E.-LIE, T. T.: A Transmission Line Model for High-Frequency Power Line Communication Channel, IEEE Transactions (2000), 1290-1295.

14] ESMAILIAN, T-KSCHISCHANG, F-GULAK, G. : In-Building Power Lines as High-Speed Communication Channels: Channel Characterization and a Test Channel Ensemble, International Journal of Communication Systems (2003).

15] BABIC, M.-HAGENAU, M.-DOSTERT, K.-BAUSCH, J. : Theoretical Postulation of PLC Channel Model, Open PLC European Research Alliance (OPERA), 2005.

Received 29 June 2010

Petr Mlýnek was born in 1983. Ing degree in 2008 (FEKT VUT Brno). His masters thesis deals with testing security of the communication unit LAN of remote data acquisition against attacks from the Internet. Currently, he is a student at $\mathrm{PhD}$ degree. His current research interests include communication over the power line channel.

Jiří Mišurec Ing (MSc) in 1985, (BUT), PhD in 1991, (BUT). His dissertation dealt with accuracy enhancement of voltage-to-frequency converters. In this period he coauthored 7 patent-author certificates. After completing his post-graduate studies he joined the Departnennt of Telecommunications as an Assistant Professor, where he gave lectures in and lead the exercise for the course Microprocessor technology in telecommunications. From 1997 to 2004 he was an employee in E.ON a.s. Brno, but he has participated in the research and teaching at FEEC BUT. Now he is again fully employed in FEEC BUT and he gives lectures in and leads the exercise for the subject Analog technique and give the lectures in the course Digital Signal Processing. His research interest is focused on the area of analog technique, converters, especially on converters working both in voltage and current mode. Now he is interested in generalization of sensitivity analysis of transfer functions. This should be used for comparison of newly developed applications. In the latest he also cooperates with a number of companies on implementation of fundamental research results into practise.

Martin Koutný received MSc at the Department of Telecommunications at the Faculty of Electrical Engineering and Computer Science at Brno University of Technology in 2007. He is currently a PhD student at the Faculty of Electrical Engineering and Computer Science at Brno.

Miloš Orgoň was born in Piešt'any, Slovakia, in 1956. He received the Master degree and $\mathrm{PhD}$ degree from the Faculty of Electrical Engineering and Information Technology, Slovak University of Technology in Bratislava in 1980 and 1988, respectively. Nowadays he works as an associate professor at the Department of Telecommunications of FEI STU Bratislava. He has been engaged in the research and development of telecommunication networks and services in liberalized environment for the area of convergent technologies. At present he is engaged in the research of the optimal design of networks and technological components, implementation of functions, services and applications and data security in projects VEGA No. 1/0565/09 "Modelling of traffic parameters in NGN telecommunication networks and services" and ITMS 26240120005 Support for Building of Centre of Excellence for SMART technologies, systems and services. 